TURIZAM

Volume 23, Issue 2

$107-119$ (2019)

ORIGINAL

SCIENTIFIC PAPER

\section{Tourism, Personality, and Risky Behaviors among Ukrainian Adolescents}

\author{
Nicholas Hryhorczuk ${ }^{A}$, Alexander Zvinchuk ${ }^{B}$, Zoreslava Shkiriak-Nyzhnyk ${ }^{B}$, \\ Liudmyla Slobodchenko ${ }^{B}$, Alla Matsola ${ }^{B}$, Daniel Hryhorczuk ${ }^{C}$ \\ Received: February 2019 | Accepted: August 2019 \\ DOI: 10.5937/turizam23-21982
}

The aim of this paper was to determine whether engagement in tourism is associated with risky behaviors among Ukrainian adolescents. The study sample consisted of 1075 adolescents who were enrolled in the "Family and Children of Ukraine" birth cohort study. They self reported how they prefer to spend their leisure time as well as their smoking, drinking, and sexual behaviors. The adolescents also completed the revised Eysenck Personality Inventory (EPI). Engagement in tourism was not associated with smoking or alcohol use. It was associated with ever having had sexual relations $(O R=1.63 ; p=0.022)$ and with having had recent sexual relations $(O R=1.67 ; p=0.037)$. These associations were stronger for males than females. Adolescents who had ever had sexual relations and those who had recent sexual relations had significantly higher extraversion scores on the EPI than adolescents who had not (18.16 vs 16.65; $p=0.002$ and 18.45 vs 16.72; $p=0.002$, respectively). In multivariable analyses, ever having sexual relations and having recent sexual relations were significantly associated with male gender, age, and marginally associated with extraversion, but not with tourism. The authors conclude that among Ukrainian adolescents, the association between engagement in tourism and sexual behavior is mediated by personality, specifically higher extraversion.

Keywords: Tourism, Personality, Adolescents, Risky Behavior

\title{
Introduction
}

The Choice of leisure activity is important to adolescent development. Participation in leisure activities has been associated with higher academic achievement, adolescent identity, and autonomy development (Caldwell, Faulk, 2013; Coatsworth et al., 2006; Eccles et al., 2003). Cohen (1974) identified tourism as a special form of leisure that is associated with pleasure, novelty, change, voluntariness, and non instrumentality. Adolescence is also the stage in devel-

A Department of Family and Consumer Sciences, College of Health and Human Sciences, DeKalb USA

B Institute of Pediatrics, Obstetrics, and Gynecology; Kyiv, Ukraine

c Center for Global Health, University of Illinois College of Medicine, Chicago, USA

* Corresponding author: nhryhorczuk@niu.edu 
opment when children begin to experiment with risky behaviors such as alcohol, smoking, and initiation of sexual relations. Travel removes social mores in place at home, and is often associated with risk-taking behavior including alcohol, drugs, and sexual contact (Rogstad, 2018). The aim of this paper is to investigate whether engagement in tourism by adolescents from Kamianske, Ukraine increases their risk of alcohol use, smoking, and having sexual relations.

Tourism accounted for 1.5\% of GDP in Ukraine in 2017 ("Tourism accounts for $1.5 \%$ of Ukraine's GDP in 2017 - Economic Development Ministry," 2018). Ukraine experienced a dramatic change in the organization of tourism opportunities and services after gaining independence in 1991. Prior to this date, there was a state monopoly in the tourism industry of the former Soviet Union (Mazaraki, Voronova, 1994). During the Soviet period, domestic tourism, including youth and children tourism was widespread (Akhmedova, 2017). After independence, state and local government support of institutions and activities in the tourism sector were reduced to a minimum. In addition, youth and children tourism is hampered by a number of negative factors which include: limited spectrum of tourism products, insufficient development of recreation and rehabilitation services, high prices, economic and political instability, limited information about the various possibilities of tourism for the mass consumer and insufficient representation of the experience, qualified personnel who can work with children. (Akhmedova, 2017). Hryhorczuk et al. (2019) observed that among adolescents in Kamianske, tourism is the least popular way for them to spend their leisure time. Despite these obstacles the World Council of Tourism and Travel predicts that the tourist market of Ukraine is going to flourish during the next 10 years (Akhmedova, 2017). The issuance of visa-free travel has increased the ease of Ukrainian tourists traveling abroad. Understanding the opportunities and obstacles for youth tourism in Ukraine is especially relevant, as this is the next generation of domestic and international tourists (Nikitenko, 2006). Perceptions that tourism is associated with risky behaviors could further impede the development of youth tourism.

In Ukraine, as in other European countries, the prevalence of weekly smoking among 15-year-olds decreased from 2002 to 2014 , from $44.7 \%$ to $14.9 \%$ for boys and from $21.4 \%$ to $8.8 \%$ for girls (Mazur et al., 2016). In the WHO Framework Convention on Tobacco Control surveys completed between 2005 and 2012, factors associated with increased overall prevalence of smoking included older age, rural residence, being married, lower education, lower socioeconomic status, and occupation (Sreeramareddy, Pradhan, 2015). Palipudi et al. (2012) analyzed data from the Global Adult Tobacco Survey that was administered in Ukraine between 2008 and 2010. Risk factors for current tobacco use in adults age 15 years and above included being male, increasing age, lower socioeconomic status, and little knowledge of smoking. Sreeramareddy and Pradham (2015) analyzed data from the Demographic and Health Survey of the WHO Framework for Convention on Tobacco Control conducted in Ukraine in 2007 and found that risk factors for current smoking included age, urban versus rural residence, marital status, education, socioeconomic status, and occupation. Rahman et al. (2018) studied the influence of belief- and school-related factors among adolescents ages 13-15 in six European countries including Ukraine. Using data from the 2011 Global Youth Tobacco Survey, they found that among Ukrainian adolescents, factors that increased current smoking included older age, seeing a teacher smoke, peer influence, exposure to secondhand smoke in public places, involvement in tobacco brand promotions, and obtaining free cigarette samples. Smoking initiation by young people constitutes one of the main challenges for tobacco control (Andreeva et al., 2007). Webb et al. (2007) found that smoking initiation in Ukraine occurred primarily during the teenage years. Intervention at a young age is therefore important in combatting smoking dependence among this population. 
Alcohol use tends to emerge during adolescent years, and early adolescent alcohol use has been linked to harmful social and behavioral function throughout adolescence and into adulthood. Observations from the Health Behavior in School-aged Children (HBSC) WHO collaborative cross-national study indicate that in $2014,17 \%$ of boys and $10 \%$ of girls age 15 years drank alcohol weekly (WHO, 2018). While the prevalence has decreased significantly since 2002, use of alcohol by adolescents remains a serious health problem in Ukraine. Numerous risk factors have been associated with alcohol abuse in adolescents (Hawkins, 1992). Contextual factors, such as laws and cultural norms; availability; socioeconomic situation; and neighborhood disorganization. Individual and interpersonal factors include sensation seeking; genetics; family behavior, attitudes and conflicts (Sumskas, Zaborskis, 2017); low commitment to school; peer rejection; alienation and rebelliousness; and association with substance-abusing peers. Observations from the Health Behavior in School-aged Children (HBSC) WHO collaborative cross-national study indicate that in 2014, $17 \%$ of boys and $10 \%$ of girls age 15 years drank alcohol weekly (WHO, 2018). While the prevalence has decreased significantly since 2002, use of alcohol by adolescents remains a serious health problem in Ukraine.

Early initiation of sexual relations is yet another risk factor that warrants attention. Ukraine has the second largest HIV epidemic in eastern Europe and addressing safe sex practices among adolescents is critically important. Krauss et al. (2012) found that among Ukrainian youth ages 1-19 years (mean age of 15.9 years), $35.9 \%$ had sexual initiation. The mean age of initiation was 16.6 years for boys and 15.6 years for girls. Only $37.2 \%$ had used contraception methods. The most common source of sexual knowledge was television/internet and friends while parents were the least common source of information. Younger age at first sex has also been associated with multiple partnership and non-condom use (Pylypchuk, Marston, 2009). Unsupervised travel may offer adolescents opportunities to engage in unsafe sex practices.

Engagement in tourism and engagement in risky behaviors may be mediated through similar personality traits. The main personality scales that have been previously applied to tourism research include the Eysenck personality scales, the Plog psychocentric/allocentric scale, and Zuckerman's sensation seeking scale. Plog's (1972) original model matched people and places with their psychographic characteristics which jumpstarted the merger between psychology and tourism research. Plog categorized tourists on an allocentric/psychocentric scale. According to Plog, allocentrics prefer less developed destinations and independent vacations, while psychocentrics prefer to travel with groups to more developed destinations. In addition to Plog's model, Zuckerman's (1979) Sensation Seeking Scale (SSS) is also widely applied to tourism research. For example, the SS has been tested by Wang et al. (1998) in China, Roth et al. (2005) in Germany, and Li et al. (2015) in Taiwan. Sensation seeking is a personality trait that has been linked to participation in a variety of stimulating events (Litvin, 2008), including tourist choice. In testing the relationship between risk taking, sensation seeking, and tourist behavior, Pizam et al. (2004) found that risk taking and sensation seeking had a significant effect on travel choices and behaviors. In psychology research, risk taking and sensation seeking have been tied to Eysenck's (1990) Extraversion score which were used in our study.

Extraversion and sensation seeking have also been associated with increased engagement in risky behaviors. Schmitt (2004), who sampled 16362 participants from 52 nations, showed that higher levels of extraversion were generally associated with increased risky behavior. Donohew et al. (1998), who sampled 2949 ninth grade students, showed a strong connection between sensation seeking and risky behavior. Hoyle et al. (2000) showed sensation seeking to be positively correlated with all categories of sexual risk taking. Miller et al. (2004), who used a longitudinal study showed that high extraversion was significantly related to risky sexual 
behavior. Others have also observed that the association between extraversion/sensation seeking and risky behaviors are stronger for males than for females. Greene et al. (2000) showed that males are generally more sensation seeking than females. Horvath and Zuckerman (1993) found a correlation between sensation seeking and risky behavior but only in males. Josiam et al. (1998) showed higher levels of sexual risk taking among males than females. In a meta analysis of 137 studies, extraversion was positively related to sexual activity and risky sexual behavior with age and gender as moderators of effects.

Several studies have focused on the effects of various types of leisure activities on risky behaviors. Most have focused on the benefits of structured, as opposed to unstructured leisure activities (Caldwell, Faulk, 2013). Several investigators have shown that adolescents who participate in structured leisure activities are less antisocial and less likely to smoke, use marijuana, or other drugs (Mahoney, 2000; Zaff et al., 2003; Sinha et al., 2007). Bartko and Eccles (2003) observed higher levels of academic achievement among adolescents who participate in structured leisure activities. On the other hand, Kleiber (1999) and Elkins (2003), have highlighted the benefits of unstructured activity, arguing that balance among activities provides a variety of benefits such as opportunities for self-expression, destressing, and creativity.

Fewer studies have focused on the direct associations between tourism and risky behaviors. Tourism can be structured, such as group excursions, or unstructured, such as camping. Engagement in certain types of tourism has been associated with risky behaviors, such as sexual activity in leisure travel contexts (Berdychevsky et al., 2013). Ours is one of the first studies, to our knowledge, to look at engagement in tourism and risky behaviors among a birth cohort of Ukrainian adolescents. We hypothesize that engagement in tourism in our adolescents will be associated with risky behaviors, such as smoking, alcohol, and sexual behavior, and that these effects may be mediated, in part, through personality type.

\section{Methods}

\section{Study Sample}

The study sample consisted of 1075 adolescents and their mothers/caregivers from Kaminaske (formerly known as Dniprodzerzhinsk) who were enrolled in the Family and Children of Ukraine (FCOU) birth cohort study and who had also completed the FCOU 3 years of age assessment. The FCOU study is the Ukrainian component of the European Longitudinal Study of Pregnancy and Childhood (ELSPAC). For this subcohort, the authors originally recruited all pregnant women from the city of Kamianske from December 1992 to June 1994, and 2156 chose to participate. A total of 1467 completed the 3 years of age assessment and of these 1075 children completed the 18 years of age assessment that was used for the current survey.

\section{Survey Instruments}

FCOU mothers/caregivers completed self administered questionnaires at the time of pregnancy, at birth, child's 6 months of age, 3 years of age, and 7 years of age. In 2011 the authors administered the 18 years of age ELSPAC questionnaires to the 1075 adolescents and their mothers/caregivers in the current study. The self administered questionnaires were constructed by researchers from the Institute of Pediatrics, Obstetrics, and Gynecology in Kyiv and the University of Illinois School of Public Health on the basis of similar survey instruments 
prepared for two other ELSPAC study sites: Avon, UK (the ALSPAC study) and Brno, Czech Republic (current ELSPAC coordinating center). All study instruments were translated from English into Ukrainian and/or Russian and reverse translated into English. The questionnaire data were entered and coded by the Louise Hamilton UIC Data Management Center in Kyiv, Ukraine. Data on parental age and socioeconomic status were taken from the parental questionnaire. The remainder of the data were taken from the adolescents' questionnaire.

Adolescents were asked the question: "How do you spend your free time?" Adolescents who responded that they engage in tourism frequently or sometimes were compared to adolescents who said that they never engage in tourism. In addition to the ELSPAC questionnaires, the revised Eysenck Personality Inventory (Eysenck, Eysenck, 1990, modified by Matolin, 1998) was used to measure neuroticism and extraversion. Eighty six percent of respondents completed the Ukrainian/Russian version of the questionnaire that included 24 items related to extraversion and 24 related to neuroticism.

\section{Statistical Analysis}

The Tourism (Often and Sometimes) and No Tourism (never) groups were compared on smoking, alcohol use, and sexual behavior using Chi square tests. Risky behaviors for smoking, alcohol, and engagement in sex were categorized as "ever engaged in that behavior" and, among those engaged, whether they had engaged in that behavior recently (i.e.in the last 30 days). The authors calculated the relative odds with $95 \%$ confidence intervals of engagement in tourism with each of the risky behavior variables. Analyses of tourism and sexual behavior was stratified on gender and compared using the Mantel Haenszel test. The Breslow Day test was used to test for interaction. Extraversion and neuroticism scores for the tourism and sexual behavior groups were compared using $t$ tests. The relationship between sexual behavior and engagement in tourism was analyzed using multiple logistic regression after adjusting for age, gender, and extraversion score.

This study was approved by the IRB at the University of Illinois at Chicago and the Institute of Pediatrics, Obstetrics, and Gynecology in Kyiv, Ukraine.

\section{Results}

The characteristics of the study sample are presented in Table 1. The adolescents had a mean age of 16.2 (range 15.1 to 18.2) and 50.5\% were male. Their mother's/caregivers had a mean age of 40.6 and father's a mean age of 43.0. 307 (28.6\%) reported that they engaged in tourism often or sometimes during their free time, 578 (53.8\%) reported that they never engaged in tourism, and responses for 190 (17.7\%) were missing. Sixty seven percent of the study sample had ever drunk alcohol and $35.6 \%$ had used alcohol in the past 30 days. $49.6 \%$ had ever smoked, and $35.6 \%$ had smoked in the past 30 days. $12.5 \%$ ever had sex and $8.7 \%$ sex within the past 30 days. 
Tourism, Personality, and Risky Behaviors

among Ukrainian Adolescents

Table 1. Characteristics of the Study Sample

\begin{tabular}{|c|c|c|c|c|c|}
\hline & $\mathrm{n}$ & $\%$ & Mean & Range Min-Max & SD \\
\hline Child's Age & 1075 & & 16.2 & $15.1 ; 18.2$ & 0.47 \\
\hline Mother's Age & 1075 & & 40.6 & $32.3 ; 58.8$ & 5.00 \\
\hline Father/Partner's Age & 784 & & 43.0 & $33.2 ; 65.4$ & 5.40 \\
\hline \multicolumn{3}{|l|}{ Gender } & & & \\
\hline Male & 543 & 50.5 & & & \\
\hline Female & 532 & 49.5 & & & \\
\hline \multicolumn{3}{|l|}{ Socioeconomic Status } & & & \\
\hline Above average & 464 & 43.2 & & & \\
\hline Average or below & 594 & 55.3 & & & \\
\hline Missing & 17 & 1.6 & & & \\
\hline \multicolumn{3}{|l|}{ Engage in Tourism } & & & \\
\hline Often or Sometimes & 307 & 28.6 & & & \\
\hline Never & 578 & 53.8 & & & \\
\hline Missing & 190 & 17.7 & & & \\
\hline \multicolumn{3}{|l|}{ Ever drank alcohol } & & & \\
\hline Yes & 725 & 67.4 & & & \\
\hline No & 264 & 24.6 & & & \\
\hline Missing & 86 & 8.0 & & & \\
\hline \multicolumn{3}{|c|}{ Used alcohol in past 30 days } & & & \\
\hline Yes & 383 & 35.6 & & & \\
\hline No & 532 & 49.5 & & & \\
\hline Missing & 160 & 14.9 & & & \\
\hline \multicolumn{3}{|l|}{ Ever smoked } & & & \\
\hline Yes & 533 & 49.6 & & & \\
\hline No & 507 & 47.2 & & & \\
\hline Missing & 35 & 3.3 & & & \\
\hline \multicolumn{3}{|l|}{ Smoked in past 30 days } & & & \\
\hline Yes & 383 & 35.6 & & & \\
\hline No & 532 & 49.5 & & & \\
\hline Missing & 160 & 14.9 & & & \\
\hline \multicolumn{3}{|c|}{ Ever had sexual relations } & & & \\
\hline Yes & 134 & 12.5 & & & \\
\hline No & 521 & 48.5 & & & \\
\hline Missing & 420 & 39.0 & & & \\
\hline \multicolumn{3}{|c|}{ Had sexual relations in past 30 days } & & & \\
\hline Yes & 94 & 8.7 & & & \\
\hline No & 556 & 51.7 & & & \\
\hline Missing & 425 & 39.5 & & & \\
\hline
\end{tabular}


Table 2 presents the relative odds of risky behaviors with engagement in tourism. Engagement in tourism was not associated with smoking or alcohol use. Engagement in tourism was significantly associated with ever having had sexual relations $(\mathrm{OR}=1.63 ; \mathrm{p}=0.022)$ and with having had recent sexual relations $(\mathrm{OR}=1.67 ; \mathrm{p}=0.037)$.

Table 2. Engagement in Tourism and Relative Odds of Risky Behaviors

\begin{tabular}{|l|c|c|c|}
\hline & Relative Odds & 95\% Confidence Interval & P value \\
\hline Smoking & 0.80 & $0.60-1.05$ & 0.109 \\
\hline Ever Smoked & 1.06 & $0.75-1.51$ & 0.731 \\
\hline Smoked in Past 30 Days & 1.038 & $0.741-1.454$ & $0.668-1.213$ \\
\hline Alcohol & 0.900 & $1.07-2.48$ & 0.496 \\
\hline Ever Drank Alcohol & 1.63 & $1.03-2.72$ & 0.022 \\
\hline Drank Alcohol in Past 30 Days & 1.67 & & 0.037 \\
\hline Sexual Relations
\end{tabular}

Table 3 presents the relative odds of ever having had sex and had sex within the past 30 days with engagement in tourism stratified by gender. Boys who engaged in tourism had significantly higher relative odds of ever having had sexual relations than those who had not, while the relative odds for girls was not significantly elevated. The Breslow Day test for interaction by gender was not significant $(\mathrm{p}=0.164)$, and the Mantel Haenszel gender adjusted odds ratio of 1.59 was significantly elevated $\left(\mathrm{OR}_{\mathrm{adj}}=1.59 ; \mathrm{p}=0.044\right)$. Boys who engaged in tourism were also more likely to have had sex in the past 30 days, though this odds ratio was only borderline statistically significant. The Breslow Day statistic for interaction between gender, tourism engagement, and sex in the past 30 days was not statistically significant $(p=0.539)$, and the Mantel Haenszel gender adjusted odds ratio was elevated $\left(\mathrm{OR}_{\mathrm{adj}}=1.62\right)$ but only borderline statistically significant.

Table 3. Relative odds of sexual behavior with engagement in tourism stratified by gender.

\begin{tabular}{|c|c|c|c|}
\hline & Relative Odds & 95\% Confidence Interval & $P$ value \\
\hline \multicolumn{4}{|l|}{ Ever had sexual relations } \\
\hline Boys & 1.516 & $1.113-2.066$ & 0.011 \\
\hline Girls & 1.070 & $0.698-1.639$ & 0.759 \\
\hline Total & 1.343 & $1.056-1.708$ & 0.022 \\
\hline Mantel-Haenszel Gender-Adjusted Odds Ratio & 1.588 & $1.037-2.433$ & 0.044 \\
\hline \multicolumn{4}{|l|}{ Had sexual relations in past 30 days } \\
\hline Boys & 1.409 & $1.009-1.967$ & 0.057 \\
\hline Girls & 1.187 & $0.714-1.973$ & 0.525 \\
\hline Total & 1.358 & $1.037-1.779$ & 0.037 \\
\hline Mantel-Haenszel Gender-Adjusted Odds Ratio & 1.620 & $0.986-2.663$ & 0.076 \\
\hline
\end{tabular}

The mean age for first sexual relations for adolescents who engaged in tourism was lower than those who did not engage in tourism (14.75 vs 15.9 years) and this difference was borderline statistically significant $(\mathrm{p}=0.058)$ using the $\mathrm{t}$ test. Table 4 presents the mean scores on 
the Eysenck Personality Scales by adolescent behavior. Engagement in tourism was positively and significantly associated associated with higher extraversion scores and lower neuroticism scores. The Cronbach's alpha statistics for the questionnaire used in our study was 0.541 for extraversion and 0.845 for neuroticism. Both ever had sexual relations and recent sexual relations was positively and significantly associated with higher extraversion scores, while there were no significant differences for neuroticism scores.

Table 4. Mean scores on Eysenck Personality Scales by Behavior

\begin{tabular}{|c|c|c|c|c|}
\hline Behavior & Yes & No & Difference & $\begin{array}{c}\text { P value } \\
\text { t test }\end{array}$ \\
\hline \multicolumn{5}{|l|}{ Extraversion Score } \\
\hline Engage in Tourism & 18.29 & 16.76 & 1.53 & $<0.001$ \\
\hline Ever Had Sexual Relations & 18.16 & 16.65 & 1.51 & 0.002 \\
\hline Had Sexual Relations in Past 30 Days & 18.45 & 16.72 & 1.73 & 0.002 \\
\hline \multicolumn{5}{|l|}{ Neuroticism Score } \\
\hline Engage in Tourism & 11.65 & 13.16 & -1.51 & 0.002 \\
\hline Ever Had Sexual Relations & 13.30 & 12.44 & 0.86 & 0.162 \\
\hline Had Sexual Relations in Past 30 Days & 12.81 & 12.54 & 0.27 & 0.712 \\
\hline
\end{tabular}

Tables 5 and 6 present the results of multiple logistic regression analyses of predictors of ever having had sexual relations and recent sexual relations. Ever having had sexual relations was significantly associated with older age and being male and marginally associated with extraversion score but not with engagement in tourism. Similarly, having had recent sexual relations was again associated with older age and being male and marginally associated with extraversion score but not with engagement in tourism.

Table 5. Multivariable Logistic Regression of Factors Related to Ever Had Sexual Relations

\begin{tabular}{|l|c|c|c|c|}
\hline Variable & B & SE & Exp(B) & P value \\
\hline Constant & -15.616 & 3.774 & & 0.000 \\
\hline Age in years & 0.818 & 0.234 & 2.267 & 0.000 \\
\hline Gender & 0.616 & 0.267 & 1.853 & 0.021 \\
\hline Engage in tourism & 0.402 & 0.277 & 1.496 & 0.147 \\
\hline Extraversion score & 0.067 & 0.036 & 1.070 & 0.064 \\
\hline
\end{tabular}

Table 6. Multivariable Logistic Regression of Factors Related to Having Recent Sexual Relations

\begin{tabular}{|l|c|c|c|c|}
\hline Variable & B & SE & Exp(B) & P value \\
\hline Constant & -18.990 & 4.603 & & 0.000 \\
\hline Age in years & 0.969 & 0.285 & 2.635 & 0.001 \\
\hline Gender & 0.728 & 0.320 & 2.071 & 0.023 \\
\hline Engage in tourism & 0.368 & 0.327 & 1.445 & 0.260 \\
\hline Extraversion score & 0.086 & 0.045 & 1.090 & 0.056 \\
\hline
\end{tabular}




\section{Discussion}

In this study sample of Ukrainian adolescents, the authors observed that those who choose to engage in tourism as a leisure activity were significantly more likely to have ever had sex and to have had sex within the past 30 days than those who never engage in tourism. These associations were stronger for boys, than for girls. Other risky behaviors, including alcohol use and smoking, were not associated with engagement in tourism. When the authors looked at personality as a possible mediator of these associations, extraversion was a significant predictor of sexual behavior. Once these associations were adjusted for age, gender, and extraversion, tourism was no longer associated with ever having sex or having had sex within the past 30 days.

Age, gender, and extraversion are known risk factors for initiation of sexual behavior. Sexual initiation is associated with age and pubertal development (Goodson et al., 1997). The median age of initiating sexual intercourse among adolescent men averages about one year earlier than women (Santelli, Beilenson, 1992). Extraversion has also been shown to be positively related to sexual activity and risky sexual behavior in previous studies (Hoyle et al., 20oo; Miller, 2004; Allen et al., 2018). It is not surprising that these variables also predict sexual behavior in our sample of adolescents.

Our lack of finding direct associations between engagement in tourism as a leisure activity and risky behaviors is encouraging, since tourism offers numerous benefits to adolescents. Akhmedova (2017) highlights the many benefits for Ukrainian adolescents. These include harmonious development of personality, cultural level expansion, social maturity, intellectual and physical training, and preparation for working life activities.

The major limitations of our study are lack of specificity on type of tourism engagement, a high non response rate for certain risky behavior questions and use of an earlier version of the Eysenck Personality Inventory that was adopted for use by Russian speaking populations. The authors asked adolescents to self report how they spend their leisure time with tourism being one of the choices. The United Nations World Tourism Organization defines tourism broadly as follows: "Tourism comprises the activities of persons traveling to and staying in places outside their usual environment for not more than one consecutive year for leisure, business and other purposes." This all encompassing definition of tourism is consistent with our survey. Engagement in tourism may mean something different to Ukrainian adolescents then to adolescents from other parts of the world. For example, camping and hiking outside one's city are considered to be tourism behaviors. Tourism can take many forms, such as sports tourism, heritage tourism, and ecotourism to name just a few. The authors were also not able to differentiate between structured or unstructured tourist activities. As has been shown in the leisure literature, risks can vary depending on whether activities are structured or unstructured (Mahoney, 2000; Zaff et al., 2003; Sinha et al., 2007). It is also unclear from our study as to who makes the decision to engage in tourism, the child or the parent. Blichfeldt et al. (2010) in their interviews with Danish teenagers found that they were experienced tourists, were very active during upfront decision-making, and had a say in family destination choice. While similar research has not yet been conducted in Ukraine, it is reasonable to assume that teenagers have a choice in the types of leisure activities they pursue and that personality would affect these choices.

While there were high non response rates for some of our sensitive risky behavior questions, the results, among our respondents, are consistent with much of the previous literature. Finally, the authors also used an earlier version of the Eysenck Personality Inventory compared to more recent revisions. This version of the EPI was included in our FCOU study by Ukrain- 
ian adolescent psychologists because it was still in wide clinical use at the time of our survey. The internal consistency of this questionnaire ranged from poor for extraversion to acceptable for neuroticism. Despite the shortcomings of this instrument, the findings on the associations of extraversion with tourism and sexual behavior are consistent with those of other studies.

This study contributes to the literature on engagement in tourism, risky behavior and personality by adding a cohort of Ukrainian adolescents, a population that is generally under represented in tourism research. While engagement in tourism theoretically offers opportunities for engagement in sexual activity for adolescents, the authors found that engagement in tourism was not a predictor of sexual behavior after adjusting for age, gender, and extraversion. While our present study is a cross sectional assessment of personality, risk taking, and tourism behavior in adolescents, the longitudinal birth cohort design allows for future analyses on factors associated with tourism choices and risky behaviors. Youth tourism in Ukraine is an understudied area of tourism research. Moreover, tourism is one of the least popular leisure time activities among Ukrainian adolescents. Ukraine ranks well below other eastern European countries in the development of its tourism industry. Given that Ukrainian youth are the next generation of domestic tourists, additional studies are needed to identify their motivations and obstacles for engaging in tourism as a leisure time activity.

\section{References}

Akhmedova, O. 2017. State Regulation of the youth and children tourism development in Ukraine. Bulletin of the National University of Civil Protection of Ukraine 1(6), 82-87.

Allen, M.S., Walker, E.E. 2018. Linking beg five personality traits to components of human sexuality and sexual health: A meta-analytic review. Psychological Bulletin 144(10). 1081-1110

Andreeva, T. I., Krasovsky, K. S., Semenova, D. S. 2007. Correlates of smoking initiation among young adults in Ukraine: a cross-sectional study. BMC Public Health 7(106).

Arnett, J. J. 1996. Sensation seeking, aggressiveness, and adolescent reckless behavior. Personality and Individual Differences 20(6), 693-702.

Bartko, W. T., Eccles, J. 2003. Adolescent participation in structured and unstructured activities. A person-oriented analysis. Journal of Youth and Adolescence 32, 233-241.

Berdychevsky, L., Gibson, H., Poria, Y. 2013. Women's sexual behavior in tourism: Loosening the bridle. Annals of Tourism Research 42, 65-85.

Blichfeldt, S. B., Pedersen, B., Johansen, A., Hansen, L. 2010. Tween tourists: children and decision-making. Journal of Tourism Consumption and Practice 2(1).

Caldwell, L. L., Faulk, M. 2013. Adolescent leisure from a developmental and prevention perspective. Positive Leisure Science: From Subjective Experience to Social Contexts (pp. 41-6o). Spring Science + Business Media.

Coatsworth, J. D., Palen, L., Sharp, E. H., Ferrer-Wreder, L. 2006. Self-defining activities, expressive identity and adolescent wellness. Applied Developmental Psychology 10, 157170.

Cohen, E. 1974. Who is a tourist? A conceptual clarification. Sociological Review 22(4), 527-555.

Donohew, L., Zimmerman, R., Cupp, P. S., Novak, S., Colon, S., Abell, R. 20oo. Sensation seeking, impulsive decision-making, and risky sex: implications for risk-taking and design of interventions. Personality and Individual Differences 28, 1079-1091.

Eccles, J. S., Barber, L. B., Stone, M., Hunt, J. 2003. Extracurricular activities and adolescent development. Journal of Social Issues 59(4), 865-889. 
Elkins, D. 2003. The overbooked child: Are we pushing our kids too hard? Psychology Today 36(1), 64-69.

Eysenck, H. J., Eysenck, S. B. G. 1969. Personality Dimensions in Children Personality Structure and Measurement (First ed., pp. 265-316). San Diego, California: Robert Kanpp.

Eysenck, H. J. 199o. Biological dimensions of personality. In L. A. De Pervin (Ed.), Handbook of personality: theory and research (pp. 246). New York: Guilford.

Goodson, P., Evans, A., Edmundson, E. 1997. Female adolescents and onset of sexual intercourse: a theory-based review of research from 1984-1994. Journal of Adolescent Health, 23(3):147-56.

Greene, K., Krcmar, M., Walters, L. H., Rubin, D. L., Hale, J. L. 20oo. Targeting adolescent risk-taking behaviors: The contributions of egocentrism and sensation-seeking. Journal of Adolescence 23, 439-461.

Hawkins, J. D., Catalano, R. F., Miller, J. Y. 1992. Risk and Protective Factors for Alcohol and Other Drugs Problems in Adolescence and Early Adulthood: Implications for Substance Abuse Prevention. Psychological Bulletin 112 (1), 64-105.

Horvath, P., Zuckerman, M. 1993. Sensation seeking, risk appraisal, and risky behavior. Personality and Individual Differences 14, 41-52.

Hoyle, R. H., Fejfar, M. C., Miller, J. 20oo. Personality and sexual risk taking: a quantitative review. Journal of Personality 68(6), 1203-1231.

Hryhorczuk, N., Zvinchuk, A., Shkiriak-Nyzhnyk, Z., Gonzales, N., Hryhorcuzk, D. 2019. Leisure activity and alcohol use among Ukrainian adolescents. Addictive Behaviors Reports 10, $1-5$.

Josiam, B., Hobson, P., Dietrich, U., Smeaton, G. 1998. An analysis of the sexual, alcohol and drug related behavioural patterns of students on spring break. Tourism Management 19(6), 501-513.

Kleiber, D. A. (1999). Leisure experience and human development: A dialectical interpretation. New York: Basic Books.

Krauss, H., Bogdanski, P., Szulinska, M., Malewski, M., Buraczynska-Andrzejewsk, B., Sosnowski, P., Piatek, J., Demont, C., Kaczmarek, C., Kaczmarek, E., Szpakow, A., Kleszczewska, E., Maciorkowska, E., Klimber, A., Mikrut, K. 2012. Sexual initiation of youths in selected European countries compared with their sexual and contraceptive knowledge. Annals of Agricultural and Environmental Medicine 19(3), 587-592.

Li, C.-Y., Lu, S.-Y., Tsai, B.-K. 2015. The impact of extraversion and sensation seeking on tourist role. Society for Personality Research 43(1), 75-84.

Lissek, S., Baas, J. M. P., Pine, D. S., Orme, K., Dvir, S., Rosenberger, E., Grillion, C.

(2005). Sensation seeking and the aversive motivational system. Emotion 5(4), 396-407.

Litvin, S. 2008. Sensation seeking and its measurement for tourism research. Journal of Travel Research 46, 440-445.

Mahoney, J. L. 2000. School extracurricular activity participation as a moderator in the development of antisocial patterns. Child Development 71(2), 502-516.

Matolin, T.V. (1998) Method of express - diagnostics of characterological traits of personality. In D.Ya. Raigorodsky (Ed.) Practical psychodiagnostics. Methods and tests. (pp.672) Samara: Publishing House "Bakhrakh".

Mazaraki, A., Voronova, E. 1994. Structure of tourism in Ukraine. Tourism Management 15(3), 230-231. 
Miller, J. D., Lynam, D., Zimmerman, R., Logan, T.K., Leukefeld, C., Clayton, R. 2004. The utility of the five -factor model in understanding risky sexual behavior. Personality and Individual Differences 36, 1611-1626.

Nikitenko, S. 2006. Development of youth and children's tourism in an independent Ukraine: problems and prospects. Scientific Works 49(62), 64-68.

Pizam, A., Jeong, G., Reichel, A., Van Boemmel, H., Lusson, J., Steynberg, K., et al. 2004. The relationship between risk taking, sensation seeking and the tourist behavior of young adults: A cross cultural study. Journal of Travel Research 42, 251-260.

Plog, S. 1972. Why destination areas rise and fall in popularity. The Cornell Hotel and Restaurant Administration Quarterly 14(4), 55-58.

Pylypchuk, R., Marston, C. 2009. Factors associated with sexual risk behavior among young people in Ukraine. Central European Journal of Public Health 16(4), 165-174.

Rahman, M., Ghasemi, Y., Zhou, Y. 2018. Adolescent smoking behavior in European countries: Influences of belief-and school-related factors. EC Paediatrics 7(6), 489-497.

Rogstad, K. 2018. Sexually transmitted diseases and travel. Current Opinion in Infectious Diseases 32(1), 56-62.

Roth, M., Schumacher, J., Brahler, E. 2005. Sensation seeking in the community. Sex, age and sociodemographic comparisons on a representative German population sample. Personality and Individual Differences 39, 1261-1271.

Santelli, J., Beilenson, P. 1992. Risk factors for adolescent sexual behavior, fertility, and sexually transmitted diseases. Journal of School Health 62(7):271-279.

Schmitt, D. (2004). The big five related to risky sexual behavior across 10 world regions: differential personality association of sexual promiscuity and relationships infidelity. European Journal of Personality, 18, 301-319.

Sinha, J. W., Cnaan, R. A., Gelles, R. J. 2007. Adolescent risk behaviors and religion: Findings from a national study. Journal of Adolescence 30(2), 231-24.9.

Smith, S. L. J. 1990. A test of Plog's allocentric/psychocentric model: evidence in seven nations. Journal of Travel Research 28(4), 40-43.

Sreeramareddy, C. T., Pradhan, P. M. 2015. Prevalence and social determinants of smoking in 15 countries from north Africa, central and eastern Asia, Latin American and Caribbean: Secondary data analyses of demographic and health surveys. Plos One.

Sumskas, L., Zaborskis, A. 2017. Family Social Environment and Parenting Predictors of Alcohol Use among Adolescents in Lithuania. International Journal of Environmental Research and Public Health 14. (19), 1037.

Tourism accounts for 1.5\% of Ukraine's GDP in 2017 - Economic Development Ministry (2018). Retrieved from https:/www.ukrinform.net/rubric-economy/244.2369-tourism-accountsfor-15-of-ukraines-gdp-in-2017-economic-development-ministry.html

Um, S., Crompton, J. 1990. Attitude determinants in tourism destination choice. Annals of Tourism Research 17(3), 432-438.

Wang, W., Wu, Y.-X., Peng, Z.-G., Lu, S.-W., Yu, L., Wang, G.-P. 20oo. Test of sensation seeking in a Chinese sample. Personality and Individual Differences 28, 169-179.

Webb, C. P. M., Bromet, E. J., Tintle, N. L., Schwartz, J. E., Gluzman, S., F., Kostyuchenko, S., Havenaar, J. M. 2007. Smoking initiation and nicotine dependence symptoms in Ukraine: Findings from the Ukraine World Mental Health Survey. The Royal Institute of Public Health 121, 663-672.

World Health Organization. Inchley J. Currie D., Vieno A., Torsheim T., Ferreira-Borges Ca, Weber M.M., Barnekow V., Breda J. (Eds). Adolescent Alcohol-related Behaviors: Trends 
and Inequalities in the WHO European region, 2002-2014 (2018). http://www.euro.who. int/_data/assets/pdf_file/ooo7/38284o/WH15-alcohol-report-eng.pdf?ua=1 Accessed March 13, 2019.

Zaff, J. F. Moore, K. A., Papillo, A. R., Williams, S. 2003. Implications of extracurricular activity participation during adolescence on positive outcomes. Journal of Adolescent Research 18(6), 599-630.

Zuckerman, M. (1979). Sensation seeking: Beyond the optimal level of arousal. Hillsdale, NJ: Erlbaum. 